\title{
A GÊNESE DO CAPITALISMO EM CAIO PRADO JÚNIOR E RAYMUNDO FAORO: APRENDENDO UMA LIÇÃO COM OS DONOS DO PODER
}

\author{
John Heulyson Ferreira de Sousa Nunes \\ Mestrando em Economia, Universidade Federal do Rio Grande do Sul, \\ Rio Grande do Sul, RS, Brasil. \\ john.heulyson@ufrgs.br.
}

\begin{abstract}
RESUMO - Diversos foram os processos responsáveis pelas metamorfoses no capitalismo brasileiro que o modelaram até o estágio que é visto nos dias de hoje, alguns interpretes são chave para desvendar a maneira como esses processos foram acontecendo. Caio Prado Júnior é o grande responsável por iniciar os estudos sobre um modelo capitalista global presente desde os primórdios brasileiros enquanto Raymundo Faoro, por sua vez, nos ajuda a entender o choque para a estrutura social, política e econômica do embate constante entre o capitalismo economicamente orientado e o capitalismo politicamente orientado, além de apresentar um importante conceito que parece vigorar durante todo o desenvolvimento capitalista: o estamento burocrático. Até que ponto essas características podem ser responsáveis por alguns dos problemas observados na sociedade brasileira até os dias de hoje? Seria o peso colonial e a herança portuguesa realmente os grandes responsáveis pelos desfechos do capitalismo brasileiro?
\end{abstract}

Palavras- Chave: Capitalismo político; Desenvolvimento social; Formação brasileira.

\section{THE GENESIS OF CAPITALISM IN CAIO PRADO JÚNIOR AND RAYMUNDO FAORO: LEARNING A LESSON WITH THE DONORS OF POWER}

\begin{abstract}
Several processes were responsible for metamorphoses in Brazilian capitalism that shaped it up to the stage that is seen today, some interpreters are key to unraveling the way these processes were going. Caio Prado Júnior is responsible for initiating studies on a global capitalist model present since the Brazilian beginnings while Raymundo Faoro, in turn, helps us understand the shock to the social, political and economic structure of the constant clash between economically oriented capitalism and politically oriented capitalism, besides presenting an important concept that seems to be in force throughout the capitalist development: the bureaucratic estate.To what extent can these characteristics be responsible for some of the problems observed in Brazilian society to this day? Was the colonial weight and the Portuguese inheritance really the major responsible for the outcomes of Brazilian capitalism?
\end{abstract}

Keywords:Political capitalism; Social development; Brazilian formation.

\section{INTRODUÇÃO}

A gênese do capitalismo tem sido importante foco dos estudos históricos desde o início dos trabalhos nessa linha, e ainda assim tem sido marcada por intensos debates pelos diferentes interpretes da economia brasileira. É complicado, na verdade talvez até impossível, se encontrar um consenso a respeito do período e da maneira com que se deu o surgimento da sociedade capitalista atual, ainda que possa sim apontar uma convergência pelo menos em que o Brasil se encontra em algum ponto sob as rédeas do capitalismo. 
Cabe aqui também se entender a qual modelo de capitalismo se destina analisar. Um sistema inserido em um contexto imperialista moderno partindo do sistema colonial voltado completamente em produzir para sua metrópole e que deixa suas marcas no futuro.

\begin{abstract}
A nossa economia se subordina inteiramente a este fim, isto é, se organizará e funcionará para produzir e exportar aqueles gêneros. Tudo mais que nela existe, e que é aliás de pouca monta, será subsidiário e destinado unicamente a amparar e tornar possível a realização daquele fim essencial. (PRADO JR, 1961, p. 113)
\end{abstract}

Diversos conceitos surgem nas análises dos autores que são de extrema relevância às proposições do presente trabalho. Não é proposto aqui discutir profundamente de forma exaustiva esses conceitos, porém alguns dada a sua importância para nosso objeto de estudo são dignos de nota, como é o caso da Revolução Democrática Burguesa.

Como já era de se esperar o conceito de Revolução Burguesa carrega em si também uma série de discussões que é base para o que será abordado nesse trabalho. $\mathrm{O}$ foco principal não é apenas entender o papel da revolução na metamorfose do capitalismo e entender como ela se deu no caso brasileiro, mas também observar o sentido em que se deu essas transformações no sistema capitalista brasileiro, utilizando o escopo apresentado por Raymundo Faoro e Caio Prado Júnior.

Em Caio Prado Jr temos um Brasil contemporâneo que guarda traços do período colonial, o que obstaculiza a sua consolidação como nação. Sua linha de pensamento entra em conflito com o postulado pela esquerda da época que tentavam importar o modelo socialista oriundo de outros países ignorando quase que completamente os processos e particularidades internos.

Segundo Raymundo Faoro, em sua interpretação do Brasil, nos deparamos com semelhante problemática, porém a colonização na forma como se deu no caso brasileiro representa um entrave para todo o processo de desenvolvimento da nação de modo que não apenas a herança colonial possui um peso inegável como também o fato de ter sido colônia portuguesa tem seu próprio peso aumentando ainda mais os desafios para romper com esse processo.

O trabalho se propõe a compreender as marcas e entraves para o desenvolvimento completo do capitalismo seja como seus pares na Europa ou para um modelo completamente diverso do já conhecido. Muitas vezes o processo de evolução do sistema capitalista é tido como modernização, porém a luz do trabalho de Faoro é possível notar que há um sentido e direção nessa modernização:

\footnotetext{
Em momento algum, ele supunha que a modernização era um processo que favoreceria a todos os membros de uma dada sociedade. Não se trata, porém, de um processo de introdução de melhorias nas condições de vida da maioria da população. Ela significa, sim, um projeto de mudança conduzido por um grupo. (REZENDE, 2006, p. 210)
}

Um dos aspectos mais interessantes do trabalho está na visão em que o capitalismo propriamente dito tal qual o desejo dos liberais clássicos de um mercado livre seria a solução 
natural na superação do problema gerado pelo estamento burocrático que se formaria no Brasil como uma das heranças coloniais de Portugal, como expressado no trecho abaixo:

\begin{abstract}
No contexto liberal, teoricamente dominante, malgrado o domínio conservador dos gabinetes, a herança mercantilista envolve, controla e tritura os desígnios dos estadistas. (FAORO, 2012, p. 440)
\end{abstract}

O artigo conta com mais quatro sessões além dessa sessão introdutória, sendo a primeira delas destinada a se discutir a visão de Caio Prado Júnior sobre a estrutura do capitalismo colonial; na segunda sessão, temos a abordagem de Raymundo Faoro sobre o importante papel da colonização portuguesa e como esta impactou no processo de formação brasileiro; na terceira sessão, entendemos um pouco mais sobre o papel do capitalismo nesse processo de formação enquanto na última sessão temos as considerações finais, com uma visão geral sobre o assunto, suas problemáticas e possíveis estudos futuros.

\title{
O MOVIMENTO DO CAPITALISMO COLONIAL
}

A expressão "Capitalismo Colonial" foi cunhada nos trabalhos de Caio Prado Júnior e se baseia numa assimilação retorcida do modelo capitalista europeu pelos primeiros habitantes do Brasil. Tenta traduzir dessa forma o processo de acumulação capitalista apresentado pelo cenário brasileiro no período colonial, demonstrando que mesmo com todas as diferenças estruturais no modelo de acumulação nacional em comparação ao europeu já era possível considerá-lo um modelo capitalista.

É com tal objetivo, objetivo exterior, voltado para fora do país e sem atenção a considerações que não fossem o interesse daquele comércio, que se organizarão a sociedade e a economia brasileiras. Tudo se disporá naquele sentido: a estrutura bem como as atividades do país. (PRADO JR, 1961, p. 26)

Prado Jr aponta em meio a esse debate dentre as especificidades da colônia a força para acelerar e ampliar o processo de acumulação mercantil derivada da Europa além da sua capacidade de se auto sustentar e perdurar por tantos anos. Para que seja possível compreender essa conceituação é necessário se entender a dinâmica internacional que vinha sendo colocada nas discussões, por exemplo, na abordagem cepalina do que mais tarde ficaria conhecido como Capitalismo Global.

Segundo Lima (2008), o conceito de dualismo toma um papel fundamental ao apontar a ideia de desenvolvimento econômico desigual a um nível global caracterizando a agricultura pré-capitalista e latifundiária como o setor retardatário e a indústria como setor moderno, ou seja, capitalista.

Logicamente as ideias aqui tratadas só se tornavam possíveis quando se colocavam em contraponto a visão do Marxismo Clássico da época, teorias difundidas pelo Partido Comunista 
Brasileiro (PCB), sobre as fases do capitalismo em que colocavam a ruptura que deveria existir para a nação passar de um sistema feudal para o capitalismo de fato. Inicialmente,o próprio Caio Prado Jr simpatizava com essa teoria chegando inclusive a aceitar que o modelo de capitanias hereditárias adotado pelos colonizadores de Portugal se baseava em um modelo feudalista:

O regime das capitanias foi em princípio caracteristicamente feudal. Não gozavam os donatários de nenhum direito sobre a terra, vedando-lhes mesmo expressamente os forais a posse de mais de dez léguas (alguns dezesseis) de terra. (PRADO JR, 1953, p. 13)

Porém o projeto de feudalismo brasileiro acabou por não conseguir se estabelecer de fato, nas palavras do próprio autor o feudalismo não vingou por não ser compatível com o sistema da colonização de modo a se tornar irrelevante ao processo histórico da formação do Brasil.

O motivo mais pesaroso dado pelo autor para desqualificar o modelo brasileiro do período colonial como sistema feudalista está nos ditames da própria propriedade. Segundo Prado (1953), para o Brasil colonial a simples propriedade da terra separada da posse dos meios necessários para explorá-la não significaria nada e essa é a principal diferença com o sistema feudal observado na Europa. O feudalismo europeu se impôs sobre uma população densa que já se dedicava a agricultura cabendo aos conquistadores apenas a apropriação do solo para gerar seu poder econômico e político, que automaticamente gerava também a relação de dependência dos tidos servos para com os senhores feudais.

No Brasil não houve essa sobreposição de estruturas, em verdade foi necessário se trazer escravos para se utilizar como mão de obra para a execução dos trabalhos necessários para a colônia. Por esse motivo não se pode, como é feito no feudalismo, caracterizar todo o poder econômico e político a mera posse e apropriação das terras, mas também de todos os investimentos nos meios para se fazer o trabalho na terra.

Outra característica de grande importância nessa justificava vem a ser o modelo adotado para a exploração das terras. Não há discussão quando se fala que no sistema europeu se via prioritariamente, quase que exclusivamente na verdade, pequenas propriedades produzindo para subsistência tendo da sua produção tributos recolhidos que eram apropriados pelo senhor feudal. Isso também não se deu no caso brasileiro. A produção em sua grande maioria era constituída das grandes propriedades que produziam para exportar para a metrópole, de modo que quase tudo que era produzido durante os ciclos coloniais brasileiros era mandado pra fora. (PRADO JR, 1961)

Graças a essa nova perspectiva adotada pelo autor ele é acaba percebendo os acontecimentos após 1930 como crises desse sistema maior e internacional. Dessa forma as mudanças geradas no Brasil naquele período nada mais foram do que impulsionadas pelas necessidades do sistema capitalista imperialista em se sustentar, como apontada a seguir: 
Enfim, insiste que o sistema colonial agrava a sua crise, considerando-se o desenvolvimento natural e espontâneo do capitalismo. Por fim, a saída para a burguesia não seria outra que o aprofundamento da associação com o imperialismo. (DEL ROIO, 2016, p. 5)

Cabe lembrar também o papel da escravidão em meio a esse processo, uma vez que diferente do pensamento hegemônico a época, Prado Jr afirmava que o modelo escravista que vigorou na prática até meados do século XIX não era incompatível com o capitalismo que se inseria no Brasil, destacando que não ouve uma ruptura no modelo de produção após a abolição dos escravos uma vez que a substituição da mão-de-obra escrava não afetou profundamente a estrutura do sistema capitalista.

Para justificar essa tesa, Prado Jr (1961) aponta as características do trabalho escravo que se aproximavam do trabalho assalariado e não da relação servil de um sistema feudal, eram elas: as grandes propriedades como já mencionada, a organização do trabalho era coletivo e cooperativo, e havia 'remuneração' fosse com dinheiro ou com bens que levavam os escravos a buscar um aumento dessas 'remunerações'. Desta forma, o escravismo era compatível ao processo de acumulação de capitais, caracteristica chave em um sistema capitalista.

Sendo assim não há dúvidas sobre os objetivos e o principal foco da revolução burguesa na ótica do autor viria a ser a confrontação ao modelo imperialista, uma vez que este não visava de fato o desenvolvimento nacional brasileiro, mas sim a manutenção do sistema global capitalista.

\section{ESTAMENTO BUROCRÁTICO E A TRANSIÇÃO CAPITALISTA}

$\mathrm{Na}$ ótica adotada por Raymundo Faoro em seu livro “Os Donos do Poder” (2012), munido de um aparato weberiano, desde o seu início também se faz uma separação entre o sistema feudal e o sistema capitalista, sendo essa separação na análise do autor fundamental para a sua interpretação do Brasil.

Segundo Faoro (2012), semelhante ao apontado por Prado, o cerne dessa diferença está na propriedade dos meios de produção. Por maiores que sejam as semelhanças encontradas nos regimes feudais europeus com o sistema colonial brasileiro, ou mesmo da américa latina, é impossível negar que nos primeiros não havia de fato uma restrição quanto a adoção, apropriação ou propriedade dos meios de produção, na verdade em muitos casos o próprio lavrador para o campo e artesão para a cidade eram donos dos meios de produção, de modo que eram os únicos responsáveis pela sua própria produção. Essa é uma característica que é talvez incompatível com o sistema capitalista, pois esse controle dos meios de produção por parte de alguém é fundamental para o funcionamento do sistema.

O grande diferencial do autor está em buscar as origens desse modelo colonial próprio estabelecido no Brasil, que difere tanto do feudalismo quanto do que seria o capitalismo 
clássico, nas bases da metrópole portuguesa. Neste ponto, se faz importante entender a diferença clássica no que precedeu o capitalismo português em relação ao resto da Europa.

A principal diferença entre esses modelos estava no arranjo econômico organizacional que fazia com que o rei português fosse dono de tudo e sua legitimidade em concessões aos servos fossem a chave para a formação dessa estrutura que ficou conhecida como patrimonialismo:

A propriedade do rei - suas terras e seus tesouros - se confunde nos seus aspectos público e particular. Rendas e despesas se aplicam, sem discriminação normativa prévia, nos gastos de família ou em obras e serviços de utilidade geral. (FAORO, 2012, p. 29)

Em cima disso, o autor elucida a incompatibilidade do feudalismo com as leis da apropriação, que para o caso português e no semelhante herdado pelo Brasil, intensifica e racionaliza o Estado o tornando forte e central a demais das muitas forças descentralizadoras que o rodeiam. Ou seja, a noção motora da monarquia portuguesa guiada pelo processo da apropriação das riquezas auferidas pelo comércio a tornava incapaz de separar o que era Estado e o que era de propriedade do rei, colocando ambos na mesma categoria tornando assim o rei absoluto como dono de tudo.

A segunda característica que se faz importante para a conceituação do autor é a noção de estamento. Diferentemente da estratificação social originada na divisão de classes, a divisão por estamento responsável por criar uma camada governante burocrática onde, tal como apresenta Faoro (1993), o antagonismo da sociedade se limitaria a governantes e governados que se traduziria em uma ordem política autocrática.

Em definitivo, para o caso português, Faoro (2012) aponta que a supremacia absoluta do rei transfigurada em uma monarquia precocemente capitalista patrimonial e estamental supera uma burguesia comercial que se tornava amplamente dependente da coroa para todos os seus objetivos e feitos.

Aqui o patrimonialismo se casa perfeitamente com o estamento, se dotando de uma forte burocracia no sentido de se apropriar do cargo sem se esquecer de suas respectivas competências. Não é de se surpreender que isso barra a racionalidade e desta forma dificulta a implementação do capitalismo industrial o impedindo de florescer na sociedade, dessa forma só se permitindo a implantação de um capitalismo com uma empresa do monarca regida pela corte e um estado poderoso que a aprisiona, nesse modelo todas as possíveis atividades seriam governadas, estimuladas e aplicadas pelo soberano em benefício da nação, ou seja, de cima para baixo. Como já era de se esperar, nas palavras de Faoro (2012, p. 88):

O Estado se confunde com o empresário, o empresário que especula, que manobra os cordéis do crédito e do dinheiro, para favorecimento dos seus associados e para desespero de uma pequena faixa, empolgada com o exemplo europeu. Todo o influxo externo, de produção de bens ou de aquisição de técnicas, sofre o efeito triturador e nacionalizador do estamento, que retarda a modernização do país. 
Com as bases do Estamento Burocrático erguidas o autor compara o que teria sido chamado de feudalismo brasileiro a tudo isso que Portugal passou anteriormente e é enfático em relatar as características marcantes da herança desse estamento burocrático português no Brasil, colocando o senhor de engenho, proprietário de latifúndios e escravos, como semelhante a aristocracia ou nobreza europeia.

\section{A ESPERA PELO CAPITALISMO REAL}

Há de se observar alguns aspectos semelhantes entre os dois autores, que mesmo por vias de análise completamente diferentes chegam a uma conclusão semelhante, ao menos em partes. Até certo ponto, em ambos autores, há uma certa continuidade no que diz respeito ao que estava acontecendo no circuito internacional.

Enquanto Faoro via o Brasil como uma extensão do aparato político criado pela coroa portuguesa e transplantado de cima para baixo sem respeitar as características singulares do novo país, em Prado Jr é possível perceber uma visão mais ampla no sentido de globalização onde se entende não apenas a herança portuguesa, mas toda uma influência do desenvolvimento europeu à custa da colônia, ou seja, é representada como apenas um detalhe sob a tela maior, tal como aponta Prado Jr (1961, p. 14)

\footnotetext{
Realmente a colonização portuguesa na América não é um fato isolado, a aventura sem precedente e sem seguimento de uma determinada nação empreendedora; ou mesmo uma ordem de acontecimentos, paralela a outras semelhantes, mas independente delas. É apenas a parte de um todo incompleto sem a visão deste todo.
}

A continuidade em Caio Prado Júnior (1961) se dá como o processo evolutivo natural do sistema capitalista germinado na Europa e que necessitava se expandir para permitir a aceleração no processo de acumulação, no caso de Portugal que não dispunha de vasto território e riquezas naturais foi preciso se lançar às aventuras no desconhecido surgindo a partir disso as colônias. Aqui o processo é entendido como uma sequência necessária para uma etapa do capitalismo global, ou seja, quando o Brasil se torna colônia de Portugal ele é automaticamente inserido no circuito internacional capitalista, infelizmente numa posição nem um pouco vantajosa.

Em Faoro, por outro lado, o processo da formação brasileira se dá como apêndice de Portugal, com as mais diversas instituições, características e estrutura sendo copiadas irrestritamente de modo a criar uma estrutura política onde uma minoria governaria em função de si mesmo muitas vezes sem nem considerar o povo de qualquer forma. Essa noção, como já visto, se configura no estamento burocrático que limita todo o processo do chamado desenvolvimento endógeno cunhado por Furtado (1977). 
As visões apesar de um tanto quanto distintas não são de forma alguma contrárias e de fato podem até mesmo se complementar. O ponto fundamental em que se forma a liga para unir essas duas teses está na concepção geral do capitalismo.

O capitalismo, na visão de Prado Jr, antecede a criação da colônia no Brasil além de estar diretamente ligado aos interesses políticos na criação dessas colônias, daí o porquê de certa forma a estrutura capitalista brasileira ter sido importada da Europa, com a colonização portuguesa, e não estar nas capacidades dos brasileiros as suas metamorfoses daquele período. Faoro também aceita essa importação da estrutura econômica e política portuguesa capitalista, apesar de fazer uma forte diferenciação sobre esse modelo capitalista em questão e explicar o motivo dele ter características tão distintas do capitalismo observado no resto do mundo à época:

\begin{abstract}
Portugal se adianta na centralização e abre o caminho para um capitalismo de perfil comercial e orientado a partir do centro do poder, de cunho político, portanto. Isso, todavia, significou cortar o caminho para a plena constituição de um capitalismo orientado pela sua lógica própria de mercado, ao invés de ser pautado pela gestão estatal. (COHN, 2012)
\end{abstract}

É possível notar aqui a noção do autor sobre a distinção referente ao modelo capitalista político quanto ao modelo capitalista completo. Também se pode observar desta tese talvez um dos fundamentos que dá base para o caminho ideológico trilhado por Faoro e de como a modernização real do capitalismo poderia resolver os problemas gerados pelo estamento burocrático enxergando então no liberalismo puro a solução possível para a crise do Estado.

Infelizmente na concepção dele se torna extremamente difícil que essa ideia seja bemsucedida já que o estamento burocrático não pertence a ninguém e está em constante transformação acabando por assimilar e se adaptar a qualquer contradição que possa ser colocada diante dele.

\footnotetext{
O capitalismo politicamente orientado - o capitalismo político, ou o précapitalismo - , centro da aventura, da conquista e da colonização moldou a realidade estatal, sobrevivendo, e incorporando na sobrevivência o capitalismo moderno, de índole industrial, racional na técnica e fundado na liberdade do indivíduo - liberdade de negociar, de contratar, de gerir a propriedade sob a garantia das instituições. (FAORO, 2012, p. 633)
}

Ou seja, o capitalismo político presente desde os primórdios do Estado brasileiro ao contrário do que deveria ser o seu processo natural, regido sobre uma estrutura perfeitamente liberal, não evolui completamente para o que seria conhecido como o capitalismo moderno, na verdade ele simplesmente assimila as estruturas liberais necessárias a sua manutenção e continuam o seu ciclo para além da sociedade.

Essa característica resulta ao passar do tempo em um dilema para o liberalismo que se vê incapaz de vencer a barreira do estamento e acaba por se juntar a ele de alguma forma de modo que o liberalismo é aceito pela parcela que está fora do Estado e recusada por quem faz parte do estamento. Claro que essa resistência do estamento se deve principalmente ao fato de 
sua estrutura ter sido sobreposta em meio ao processo de formação brasileiro, fazendo com que o povo se torne incapaz de gerar uma identidade própria o que acaba dificultando as atividades do Estado fazendo com que ele se desvie do que devia ser o seu objetivo gerador, ou seja, agir em benefício da população:

O problema do liberalismo era compatibilizar-se com os estamentos, que assumem um papel semi-independente. Forma-se uma modalidade especial de liberalismo, onde a base não estará no povo, no cidadão, mas nos corpos intermediários. (FAORO, 1993, p. 26-27)

Temos então o nascimento de um novo liberalismo que tem muito pouco de democrático com a formação de um Estado que vive a parte de seu povo, uma vez que esse sistema político não partiu do povo sendo completamente formado de cima para baixo, em vias gerais tendo se erguido antes mesmo do surgimento de um povo de fato. Por conta disso, acaba se gerando uma casta de carreiristas buscando a todo custo fazer parte do estamento burocrático já que aquele seria o parâmetro máximo de elevação no cenário nacional.

Há uma necessidade de se identificar os reais impactos que a colonização portuguesa trouxe para a estrutura da sociedade brasileira e perceber até que ponto é preciso uma mudança no carácter institucional ou mesmo no perfil e identidade social do povo como um todo, ainda que seja importante uma integração para um sentido nacional como apontado por Rezende (2006, p. 226):

\footnotetext{
Tais atores políticos tinham, também, que emergir dos diversos segmentos sociais, até mesmo dos setores empresariais. Enquanto estes últimos fizerem afirmações de que seus protestos são apenas desabafos, e não um empenho questionador das ações governamentais, há uma clara indicação de que o País está ainda muito longe da constituição de um capitalismo economicamente orientado.
}

Esse aspecto vem para reforçar um pouco a necessidade de se perceber como nação já que apenas assim seria possível ter forças suficientes para alterar a estrutura do modelo capitalista em proporções suficientes para que sua ótica e orientação se modifique. Este é sem qualquer dúvida o primeiro passo para se superar o estamento burocrático.

\section{CONSIDERAÇÕES FINAIS}

Em ambas as visões abordadas nesse trabalho podemos sem qualquer dificuldade descartar a crença da existência do modelo feudal no Brasil dada a sua impossibilidade de coexistir com características chave do período colonial brasileiro, no entanto uma discussão é posta ao relacionar as duas ideias. De um lado, temos a adoção de um modelo alternativo do capitalismo, citado aqui como capitalismo colonial, que serve para representar o sistema da colônia inserido no capitalismo global dado pelas relações de troca entre Brasil e Europa, inicialmente na metrópole em Portugal e mais tarde com a Inglaterra, do outro lado temos a existência do estamento burocrático que se define em uma estrutura política e econômica incompatível tanto com o capitalismo industrial quanto com o sistema feudal. 
Caio Prado Júnior aponta os problemas originados no Brasil como efeitos do desenvolvimento do capitalismo nas pioneiras capitalistas europeias, ou seja, o Brasil Colônia chegou como extensão dos anseios capitalistas da metrópole se encaixando forçosamente no capitalismo comercial global liderado pelas nações europeias.

Pelo trabalho de Raymundo Faoro, parece perceptível o importante papel do livre mercado, apenas possível com o capitalismo moderno e industrial, para superar as dificuldades estruturais trazidas pela coroa portuguesa a tantos séculos atrás. Temos o estamento burocrático como suscetível a uma infinidade de metamorfoses durante toda a evolução histórica do Brasil, porém sem alterar de fato suas bases estruturais, de modo que o estado patrimonialista sempre colocaria uma minoria sobre o controle de todo o resto da nação.

É difícil compreender um Estado que é criado mais para servir os interesses externos, na figura da representação da coroa ou metrópole, ao invés dos interesses de seu povo, principalmente pois não havia um povo de fato ante a criação do Estado. Essa estrutura clássica do estamento burocrático é responsável por provocar um distanciamento entre a casta de líderes que parece estar em um patamar inalcançável pela população comum.

Por fim, pode-se admitir que o transplante das estruturas portuguesas nos novos domínios da coroa tem um significante impacto para todo o modelo estatal assumido no Brasil. Não apenas o país herdou um distanciamento do povo com os seus líderes como gerou uma dificuldade em se reconhecer como uma nação de fato não havendo de certa forma uma unificação, nem mesmo em um sentido de homogeneizar os interesses ainda quando isso não representasse diretamente uma melhor distribuição de renda.

Toda essa problemática envolvida acaba prejudicando o desenvolvimento do capitalismo o transformando em um amálgama de diversas sobreposições de estruturas sociais, políticas e econômicas que acabam por tornar o país dependente desse modelo capitalista em uma esfera global com entraves e limites internos para sua ruptura ou evolução. Estaria então o Brasil fadado a uma trilha constante o empurrando cada vez mais para dentro do subdesenvolvimento?

Esse trabalho cumpre o seu papel ao trazer à tona a discussão sobre as características da formação brasileira herdadas de seu contexto colonial em um capitalismo imperialista e dar luz aos talvez principais fatores responsáveis pela estruturação do atual sistema político tentando responder a clássica pergunta de a quem o Estado é responsável por servir e tentando achar soluções de mudança para um sentido diferente do apontado pelos autores. 


\section{REFERÊNCIAS}

COHN, Gabriel. Persistente Enigma.In: FAORO, Raymundo. Os Donos do Poder: Formação do Patronato Político Brasileiro. São Paulo: Globo, 2012, $5^{\text {a }}$ edição.

DEL ROIO, Marcos. Capitalismo e Revolução em Caio Prado Jr. Disponível em: <https://revistas.pucsp.br/index.php/ls/article/viewFile/31843/pdf > Acesso em:18/10/2018

FAORO, Raymundo. A Aventura Liberal numa Ordem Patrimonialista.Revista USP, São Paulo, n. 17, p.14-29, mar./abr./maio 1993.

edição.

Os Donos do Poder: Formação do Patronato Político Brasileiro. São Paulo: Globo, 2012, $5^{\text {a }}$

FURTADO, Celso. Teoria e Política do Desenvolvimento Econômico. São Paulo: Editora Nacional, $1977,6^{\text {a }}$ edição.

LIMA, Airton Souza de. Caio Prado Jr e a Polêmica "Feudalismo-Capitalismo": Pela Desconstrução de Consensos. In: Revista Aurora, $n^{\circ}$ 3, ano II, dezembro/2008

PRADO JR., Caio. A Revolução Brasileira. 1966. In: PRADO JR., Caio; FERNANDES, Florestan.Clássicos sobre a Revolução Brasileira. São Paulo: Expressão Popular, $4^{\mathrm{a}}$ edição, 2005, p 25-53.

Formação do Brasil Contemporâneo: Colônia. São Paulo: Brasiliense, 6a edição, 1961.

Evolução Política do Brasil. São Paulo: Brasiliense, 1953.

REZENDE, Maria José de. O Capitalismo Brasileiro e as Modernizações Desvinculadas da Modernidade. In: Ensaios FEE, Porto Alegre, v. 27, n. 1, p. 207-232, maio/2006. Disponível em: <https://revistas.fee.tche.br/index.php/ensaios/article/viewFile/2117/2499> Acesso em: 18/10/2018 